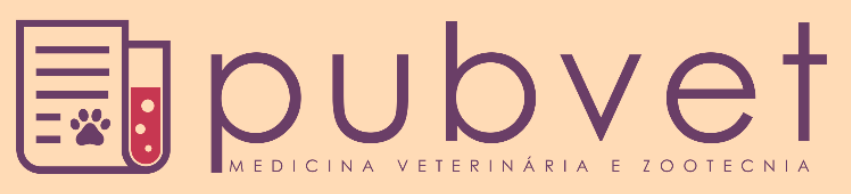

https://doi.org/10.31533/pubvet.v14n4a560.1-6

\title{
Testes alternativos para a avaliação da viabilidade fisiológica de sementes de Enterolobium contortisiliquum (Vell.) Morong
}

\author{
Weuler Alves Vasconcelos ${ }^{1 *} \bullet$, Ana Clara Alencar Lambert ${ }^{2} \bullet$, Sabrina do Couto de Miranda ${ }^{3} \bullet$, \\ Priscila Bezerra Souza $^{4} \bullet$, Sybelle Barreira ${ }^{\circ}$ \\ ${ }^{I}$ Engenheiro Florestal, Mestre em Ciências Florestais e Ambientais, Analista Ambiental na Biota Projetos e Consultoria Ambiental, Goiânia - GO, Brasil. \\ ${ }^{2}$ Engenheira Florestal na Gerência de Recursos Naturais do Instituto Brasileiro de Geografia e Estatística, Florianópolis - SC, Brasil. \\ ${ }^{3}$ Professora da Universidade Estadual de Goiás, Departamento de Botânica, Palmeiras de Goiás - GO, Brasil. \\ ${ }^{4}$ Professora da Universidade Federal do Tocantins, Programa de Pós-graduação em Ciências Florestais e Ambientais, Gurupi-TO, Brasil. \\ ${ }^{5}$ Professora da Universidade Federal de Goiás, Departamento de Engenharia Florestal, Goiânia - GO, Brasil. \\ *Autor para correspondência. E-mail: weulervasconcelos@gmail.com
}

\begin{abstract}
Resumo. Enterolobium contortisiliquum (Vell.) Morong (Tamboril) é uma espécie com ampla distribuição e uso múltiplos, sendo utilizada na recuperação de áreas degradadas. Dessa forma, objetivou-se verificar a viabilidade fisiológica de sementes desta espécie pelo teste de condutividade elétrica (CE) e do teste de tetrazólio (TZ). Para o teste de CE foram realizadas medições nos tempos $0,02,08,16,32,70$ e 80 horas de embebição em água a $25^{\circ} \mathrm{C} \mathrm{em}$ ambiente com baixa incidência de luz. Já para o teste $\mathrm{TZ}$ foi realizado imersão em solução tetrazólio a $1 \%$ por 24 horas a $30^{\circ} \mathrm{C}$ no escuro. A porcentagem de germinação pelo teste sobre papel em gerbox foi igual a $92 \%$, com peso de mil sementes para o lote igual a 634,99g e teor de umidade igual a $5,24 \%$. Os resultados obtidos no teste de CE e TZ permitem afirmar a eficiência para caracterizar a viabilidade fisiológica das sementes de E. contotisiliquum. Estudos desta natureza são importantes para verificar a viabilidade fisiológica de sementes desta espécie na região norte do município de Goiânia.
\end{abstract}

Palavras chave: condutividade elétrica, germinação, teste de tetrazólio

\section{Alternative tests for the evaluation of the physiological viability of Enterolobium contortisiliquum (Vell.) Morong seeds}

\begin{abstract}
Enterolobium contortisiliquum (Vell.) Morong is a species with extensive multiple distribution and use, being widely used in the recovery of degraded areas. Thus, the objective was to verify the physiological viability of seeds of this species through the electrical conductivity test (EC) and the tetrazolium test (TZ). For the EC test, measurements were made at times $0,02,08,16,32,70$ and 80 hours of soaking in water at $25^{\circ} \mathrm{C}$ in an environment with low light incidence. For the TZ test, immersion in a $1 \%$ tetrazolium solution was performed for 24 hours at $30{ }^{\circ} \mathrm{C}$ in the dark. The germination percentage by the test on gerbox paper was equal to $92 \%$, with a thousand seed weight for the lot equal to $634.99 \mathrm{~g}$ and moisture content equal to $5.24 \%$. The results obtained in the $\mathrm{CE}$ and TZ test allow to affirm the efficiency to characterize the physiological viability of the Enterolobium contortisiliquum (Vell.) Morong seeds, Studies of this nature are important to check the viability of seeds of forest species in the northern region of the municipality of Goiânia
\end{abstract}

Keywords: electrical conductivity, germination, tetrazolium test 


\title{
Pruebas alternativas para la evaluación de la viabilidad fisiológica de las semillas de Enterolobium contortisiliquum (Vell.) Morong
}

\begin{abstract}
Resumen. Enterolobium contortisiliquum (Vell.) Morong es una especie con amplia distribución y uso múltiple, que se utiliza ampliamente en la recuperación de áreas degradadas. Por lo tanto, el objetivo fue verificar la viabilidad fisiológica de las semillas de esta especie a través de la prueba de conductividad eléctrica (CE) y la prueba de tetrazolio (TZ). Para la prueba CE, las mediciones se realizaron en los momentos $0,02,08$, $16,32,70$ y 80 horas de remojo en agua a $25^{\circ} \mathrm{C}$ en un ambiente con baja incidencia de luz. Para la prueba TZ, la inmersión en solución de tetrazolio al $1 \%$ se realizó durante 24 horas a $30{ }^{\circ} \mathrm{C}$ en la oscuridad. El porcentaje de germinación por la prueba en papel gerbox fue igual al $92 \%$, con un peso de mil semillas para el lote igual a 634,99 $\mathrm{g}$ y un contenido de humedad igual al 5,24\%. Los resultados obtenidos en las pruebas CE y TZ permiten afirmar la eficiencia para caracterizar la viabilidad fisiológica de las semillas de Enterolobium contortisiliquum (Vell.) Morong. Los estudios de esta naturaleza son importantes para verificar la viabilidad fisiológica de las semillas de especies forestales en la región norte del municipio de Goiânia.
\end{abstract}

Palabras clave: conductividad eléctrica, germinación, prueba de tetrazolio

\section{Introdução}

Enterolobium contortisiliquum (Vell.) Morong é uma espécie arbórea de origem brasileira com ocorrência em quase todos os biomas brasileiros. É uma espécie pertencente à família Fabaceae, conhecida popularmente por Tamboril, orelha-de-macaco, orelha-de-negro, tambori, timbaúba ,timbó, tambaré, timbaúva, ximbó e pacará onde sua altura pode atingir até 35 metros apresentando perda de folhas durante o inverno em regiões secas (Lorenzi et al., 2002).

As sementes do gênero Enterolobium, quando maduras, apresentam dormência por impermeabilidade do tegumento à água, sendo necessário um tratamento de interrupção da dormência, no qual a escarificação é uma forma que permite a germinação (Melo Júnior et al., 2018). Scalon et al. (2005) afirmam que este tipo de sementes apresenta comportamento ortodoxo com $90 \%$ de germinação quando armazenadas de $3^{\circ} \mathrm{C}$ a $5^{\circ} \mathrm{C}$ e $92 \%$ UR e $50 \%$ de germinação após nove anos de armazenamento.

A espécie é amplamente empregada em áreas de reflorestamento e recuperação de áreas degradadas. Entretanto, não se sabe muito sobre os aspectos técnicos da germinação das sementes de $E$. contotisiliquum e produção de mudas na região norte do município de Goiânia, sendo necessária aplicação de testes fisiológicos para verificar a qualidade das sementes e estudos para a caracterização das mesmas. Uma alternativa para o teste convencional de germinação é o teste de condutividade elétrica, o qual sugere uma avaliação do vigor de sementes de diversas espécies com eficiência satisfatória por apresentar rapidez, facilidade de execução e possibilidade de padronização (Lemes et al., 2015; Vazquez et al., 2014). Além do teste de condutividade elétrica, o teste de tetrazólio, muito empregado em sementes agrícolas, estima a viabilidade das sementes com base na alteração da coloração dos tecidos vivos (Marcos Filho, 2005).

Dessa forma, objetivou-se caracterizar um lote de sementes de Enterolobium contortisiliquum e verificar a viabilidade fisiológica através do teste de condutividade elétrica e do teste de tetrazólio.

\section{Material e métodos}

O trabalho foi conduzido no Laboratório de Reprodução de Espécies Florestais da Escola de Agronomia da Universidade Federal de Goiás, Campus Samambaia, Goiânia-GO. Foram utilizadas sementes de Enterolobium contortisiliquum coletadas de uma árvore matriz sob as coordenadas $16^{\circ} 36^{\prime} 54,77^{\prime \prime}$ S e $49^{\circ} 17^{\prime} 6,82^{\prime \prime} \mathrm{O}$.

Para a caracterização do lote de sementes foi mensurado o peso de mil sementes, seguindo a metodologia proposta pela Regra de Análise de Sementes - RAS (Brasil, 2009), e a determinação do 
grau de umidade pelo método de estufa de fluxo forçado com quatro repetições de 25 sementes cada por 24 horas a $\pm 105^{\circ} \mathrm{C}$, conforme metodologia da RAS.

A dormência tegumentar das sementes de E. contotisiliquum foi rompida pelo método da escarificação mecânica com auxílio de lixa mecânica do tipo 6" (Pereira et al., 2014). O experimento de germinação consistiu em quatro repetições de 25 sementes cada (Brasil, 2009) dispostas em gerbox com papel mata borrão umedecido com $20 \mathrm{~mL}$ de água destilada, onde as mesmas foram organizadas em germinador de sementes modelo Mangelsdorf por 15 dias a uma temperatura de $25^{\circ} \mathrm{C}$ e luz ambiente. A manutenção da quantidade de água no papel mata borrão foi feita em dias alternados, adicionando $10 \mathrm{~mL}$. No fim do experimento foi calculado o Índice de Velocidade de Germinação (IVG) utilizando a metodologia proposta por (Maguire, 1962), com auxílio do Software Microsoft Excel 2010.

Visando mensurar a viabilidade fisiológica do lote das sementes de E. contotisiliquum, aplicaram-se os testes de condutividade elétrica e o teste de tetrazólio. Para o teste de condutividade elétrica foram usadas quatro repetições de 25 sementes por tempo de embebição, as quais foram previamente pesadas em balança semi analítica com precisão de $0,001 \mathrm{~g}$ e cada repetição sendo acondicionada em recipiente de plástico com tampa, com volumetria igual a $400 \mathrm{~mL}$, contendo $150 \mathrm{~mL}$ de água destilada, e, posteriormente, submetida a $0,02,08,16,32,70,80$ horas de embebição a $25^{\circ} \mathrm{C}$ em ambiente com baixa incidência de luz.

Decorrido cada período de embebição, efetuou-se a leitura da condutividade elétrica na solução de embebição das sementes usando um condutivímetro de bancada, modelo Tec-4MP. O valor de cada leitura de condutividade foi dividido pela respectiva massa da amostra, expressando-se os resultados de condutividade elétrica em $\mu \mathrm{Scm}^{-1} \mathrm{~g}^{-1}$ de semente. Após as medições da condutividade elétrica, foi escolhida uma repetição de cada tempo de embebição para que fosse realizado o teste tetrazólio, sendo escolhidos aqueles com valores mais distantes da média geral.

Após escolhidas, as sementes foram depositadas em recipientes de alumínio com tampa e receberam $25 \mathrm{~mL}$ da solução preparada na concentração de $1 \%$ de tetrazólio, proporcionando assim a cobertura das sementes pela solução. Os recipientes foram transferidos para uma câmara de germinação de temperatura constante calibrada em $30^{\circ} \mathrm{C}$, onde permaneceram por 24 horas no escuro. Após este período, as sementes foram abertas para avaliação da coloração nos tecidos e no eixo embrionário, passando por uma classificação de cinco faixas de coloração. Os dados e gráficos foram compilados e processados com auxílio do programa Microsoft Excel.

\section{Resultados e discussão}

O peso das mil sementes do lote da espécie Enterolobium contortisiliquum foi igual a 634,99 g com teor de umidade de 5,24\%. A germinação média das sementes de E. contotisiliquum foi de $92 \%$ e o Índice de Valor de Germinação (IVG) de 6,95. Em estudo realizado por Teles \& Barreira (2018) analisando lotes de sementes da mesma espécie obteve-se valores próximo ao deste estudo, sendo 655,5 g para o peso de mil sementes, $4,30 \%$ o teor de umidade, $83 \%$ a porcentagem de germinação e 4,89 o IVG. Brüning et al. (2011) explicam que o teor de umidade de sementes é variável por razão da desidratação natural que ocorre no processo de armazenamento de sementes ortodoxas.

Após tais análises foi realizado o teste de condutividade elétrica para o lote de sementes em questão (Figura 1). Observou-se que com o passar do tempo à condutividade elétrica se elevou pela deterioração natural causada na presença de água. Dalanhol et al. (2014) realizaram experimento com sementes de Bowdichia virgilioides Kunth e encontraram resultados parecidos com este estudo, por se tratar também de sementes com dormência do tipo tegumentar.

Este padrão (Figura 1) se dá quando as sementes se apresentam viáveis, no qual a quantidade de exsudatos lixiviados das sementes, na água de embebição, pode ser influenciada pelo grau de deterioração, pelo estádio de desenvolvimento no momento da colheita, pela incidência de danos causados pela velocidade de embebição (Loeffler, 1981), pela temperatura e tempo de embebição (Powell, 1986) e por injúrias no tegumento das sementes.

Os resultados do teste de tetrazólio, para as sementes submetidas ao tratamento a partir do teste de condutividade elétrica, estão dispostos na Tabela 1. As médias dos valores da condutividade elétrica 
aumentaram com o passar do tempo, pois as sementes em contato com a água aumentaram a liberação de solutos o que acresceu no aumento da leitura dos valores com o passar do tempo começando a decrescer no tempo de 80 horas. Esse mesmo padrão foi observado por Muraro et al. (2017) quando realizou estudos semelhantes com sementes de Panicum miliaceum L.

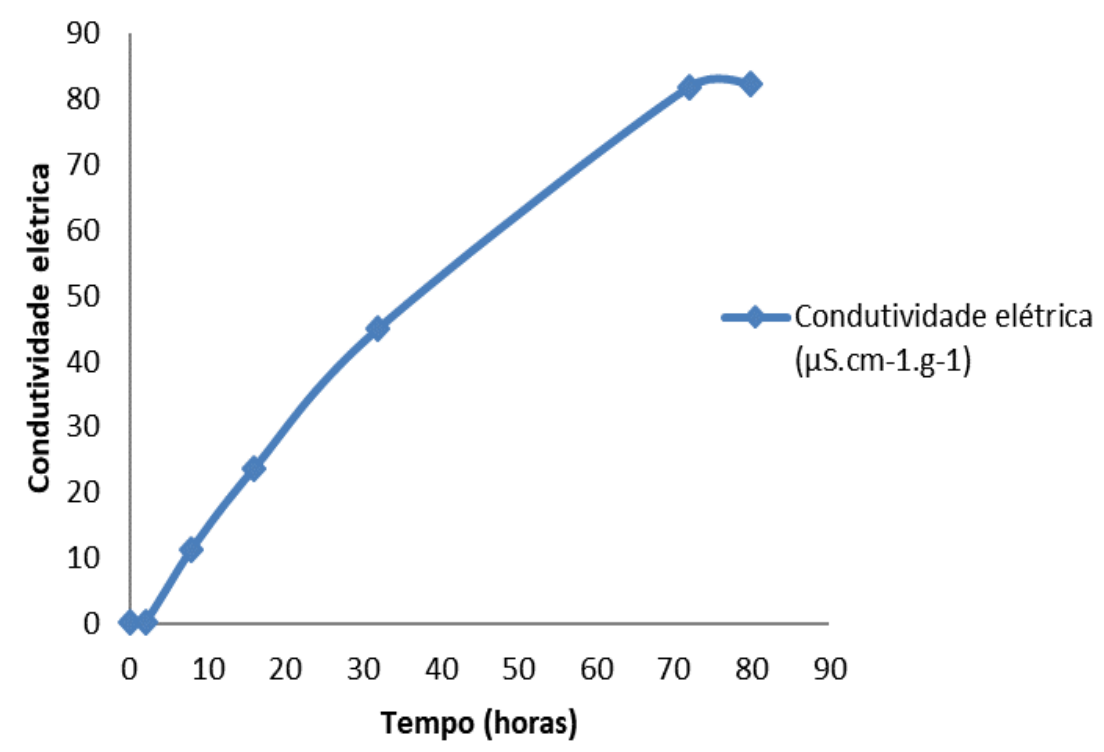

Figura 1. Condutividade elétrica das sementes de Enterolobium contortisiliquum (Tamboril), em $\mu \mathrm{S} . \mathrm{cm}^{-1}$. g ${ }^{-1}$, ao decorrer dos tempos de embebição.

O padrão de coloração das sementes de E. contotisiliquum é representado na Figura 2, no qual a coloração varia da menor coloração do eixo embrionário (1), sendo as sementes com potencial menor de viabilidade, para as sementes com maior coloração do eixo embrionário (5), sendo aquelas viáveis.

Tabela 1. Tempo (tratamento), média dos valores de condutividade elétrica (CE) por tempo das sementes de Enterolobium contortisiliquum (Tamboril), e repetição de menor valor com suas respectivas leituras de condutividade elétrica

\begin{tabular}{lccc}
\hline Tempo & Média da CE por tratamento $^{1}$ & Repetição & Valor da CE da repetição $^{1}$ \\
\hline 0 & 0,18374 & R3 & 0,173977329 \\
2 & 0,196564 & R1 & 0,172501268 \\
8 & 10,89924 & R3 & 9,183155758 \\
16 & 23,62066 & R1 & 20,00490677 \\
32 & 44,98685 & R4 & 41,61764706 \\
70 & 82,7517 & R2 & 78,05719921 \\
80 & 81,25588 & R4 & 77,06422018 \\
\hline
\end{tabular}

${ }^{1}$ Valores expressos em $\mu \mathrm{S} . \mathrm{cm}^{-1} \cdot \mathrm{g}^{-1}$ para a repetição.

As classes 3, 4 e 5 juntas representaram $88 \%$ das sementes, mostrando que a coloração do eixo embrionário pode afirmar a viabilidade das sementes por essa metodologia. Nogueira et al. (2014) trabalhando com sementes de Enterolobium contortisiliquum encontraram resultados semelhantes quando realizaram a embebição em água por 24 horas e retirada do tegumento, com posterior imersão das sementes por três horas em solução de tetrazólio de $0,075 \%$, a $35^{\circ} \mathrm{C}$.

Estudos desta natureza são importantes para verificar a viabilidade das sementes de espécies florestais visando minimizar tempo e custos para obtenção de respostas fisiológicas das sementes, facilitando assim tomadas de decisão na produção de mudas nativas a partir de sementes para a recuperação de áreas degradadas, por exemplo.

No geral, para a coloração adequada das espécies florestais são necessárias concentrações mais elevadas da solução de tetrazólio, como foi testado e comprovado nas espécies Melanoxylon brauna Schott a 0,3\% (Corte et al., 2010), Tabebuia serratifolia (Vahl) G. Nicholson a 0,5\% (Oliveira et al., 
2005), além das espécies Schizolobium parahyba (Vell.) S. F. Blake (Ferreira et al., 2007) e Ceiba speciosa (A. St.-Hil.) (Lazarotto et al., 2011).

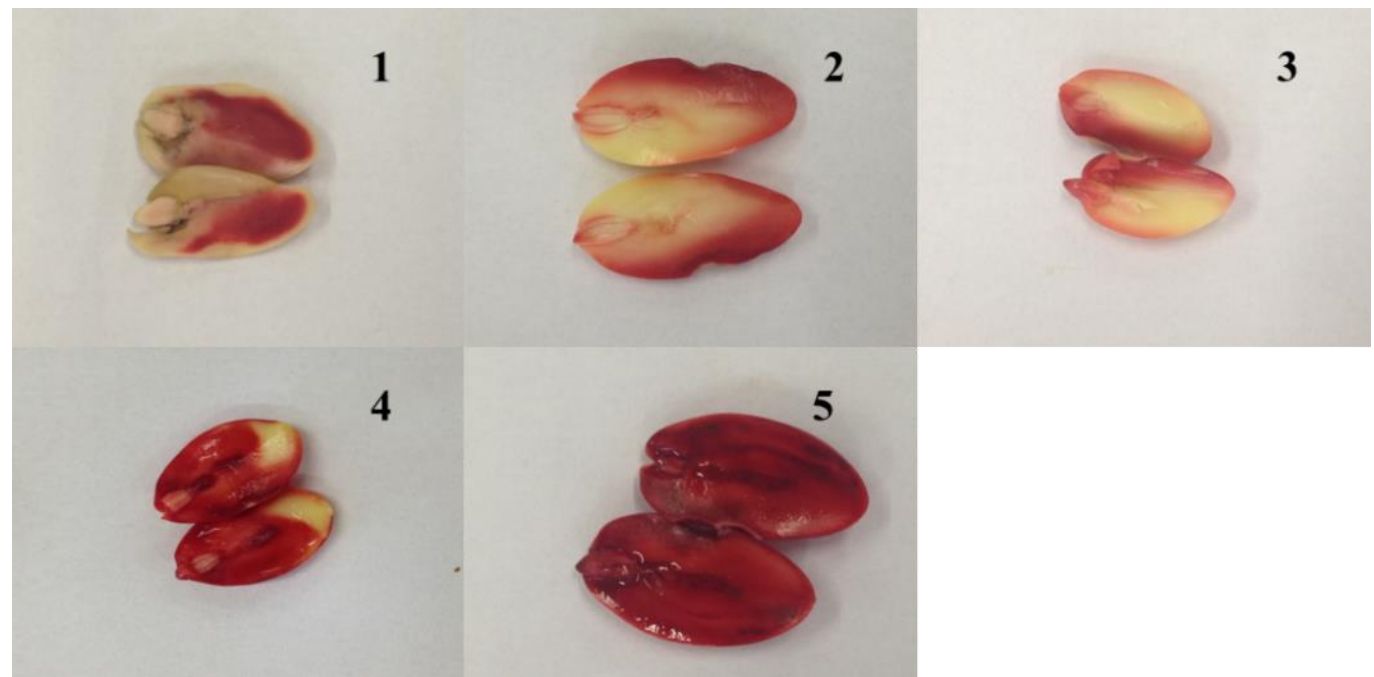

Figura 2. Níveis de pigmentação para a classificação da viabilidade em relação à coloração do eixo embrionário de sementes de Enterolobium contortisiliquum (Tamboril).

\section{Conclusão}

O peso das mil sementes do lote da espécie Enterolobium contortisiliquum foi igual a 634,99 g com teor de umidade de 5,24\%. A germinação média das sementes de E. contotisiliquum foi de $92 \%$ e o Índice de Valor de Germinação (IVG) de 6,95.

Pode-se inferir que o teste de condutividade elétrica e o teste de tetrazólio na concentração de 1\% testado nesse estudo é uma alternativa viável para avaliar, com eficiência, a viabilidade das sementes da espécie E. contortisiliquum.

\section{Referências bibliográficas}

Brasil. Ministério da Agricultura, Pecuária e Abastecimento. (2009). Regras para análise de sementes. MAPA/ACS, Brasília, DF, Brasil.

Brüning, F. O., Lúcio, A. D., \& Muniz, M. F. B. (2011). Padrões para germinação, pureza, umidade e peso de mil sementes em análises de sementes de espécies florestais nativas do Rio Grande do Sul. Ciência Florestal, 21(2), 193-202.

Corte, V. B., Borges, E. E. L., \& Pereira, B. L. C. (2010). Adequação da metodologia do teste de tetrazólio para avaliação da viabilidade de sementes de Melanoxylon brauna Schot. Cerne, 16(3), $415-421$.

Dalanhol, S. J., Rezende, E. H., Abreu, D. C. A., \& Nogueira, A. C. (2014). Teste de condutividade elétrica em sementes de Bowdichia virgilioides Kunth. Floresta e Ambiente, 21(1), 69-77. http://dx.doi.org/10.4322/floram.2014.013

Ferreira, R. A., Oliveira, L. M. de., Tonetti, O. A. O., Davide, A. C. (2007). Comparação da viabilidade de sementes de Schizolobium parahyba (Vell.) Blake - Leguminosae Caesalpinoideae, pelos testes de germinação e tetrazólio. Revista Brasileira de Sementes, 29 (3), 83-89.

Lazarotto, M. Piveta, G., Muniz, M. F. B., Reiniger, L. R. S. (2011). Adequação do teste de tetrazólio para avaliação da qualidade de sementes de Ceiba speciosa. Semina: Ciências Agrárias, 32 (4), 1243 1250. http://dx.doi.org/10.5433/1679-0359.2011v32n4p1243

Lemes, E. S., Oliveira, S., Rodrigues, R. R., Almeida, A. S., Meneghello, G. E., \& Tunes, L. M. (2015). Avaliação do potencial fisiológico de lotes de aveia preta por meio do teste de condutividade elétrica. Tecnologia \& Ciência Agropecuária, 9(2), 5-10.

Loeffler, T. M. (1981). The bulk conductivity test as an indicator of soybean seed quality. University of Kentucky. 
Lorenzi, H., Matos, F. J., \& Francisco, J. M. (2002). Plantas medicinais no Brasil: nativas e exóticas (Vol. 1).

Maguire, J. D. (1962). Speed of germination-Aid in selection and evaluation for seedling emergence and vigor. Crop Science, 2(2), 176-177.

Marcos Filho, J. (2005). Fisiologia de sementes de plantas cultivadas. FEALQ.

Melo Júnior, J. L. A., Ferreira, V. M., Araújo Neto, J. C., \& Neves, M. I. R. S. (2018). Biometric characterization and seed germination of giant mimosa [Mimosa bimucronata (DC) O. Kuntze]. Australian Journal of Crop Science, 12(1), 108-115.

Muraro, D. S., Cutti, L., Kulczynski, S. M., Basso, C. J., \& Pedroso, D. S. (2017). Teste de condutividade elétrica em sementes de painço (Panicum miliaceum L.). Revista Brasileira de Ciências Agrárias, 12(4), 490-495.

Nogueira, N. W., Torres, S. B., \& Freitas, R. M. O. (2014). Tetrazolium test in timbaúba seeds. Semina: Ciências Agrárias, 35(6), 2967-2976. http://dx.doi.org/10.5433/1679-0359.2014v35n6p2967

Oliveira, L. M. de, Carvalho, M. L. M. de, Nery, M. C. (2005). Teste de tetrazólio em sementes de Tabebuia serratifolia Vahl Nich. e T. impetiginosa (Martius ex A. P. de Candolle) Standley Bignoniaceae. Revista Ciência Agronômica, 36 (2), 169-174.

Pereira, V. J., Santana, D. G., Lobo, G. A., Brandão, N. A. L., \& Soares, D. C. P. (2014). Eficiência dos tratamentos para a superação ou quebra de dormência de sementes de Fabaceae. Revista de Ciências Agrárias, 37(2), 187-197.

Powell, A. A. (1986). Cell membranes and seed leachate conductivity in relation to the quality of seed for sowing. Journal of Seed Technology, 10(2), 81-100.

Scalon, S. de P. Q., Mussury, R. M., Wathier, F., Gomes, A. A., Silva, K. A., Pierezan, L., \& Scalon Filho, H. (2005). Armazenamento, germinação de sementes e crescimento inicial de mudas de Enterolobium contortisiliquum (Vell.) Morong. Acta Scientiarum. Biological Sciences, 27(2), 107112.

Teles, T. A. S., \& Barreira, S. (2018). Avaliação fisiológica de sementes visando projetos de restauração ecológica com semeadura direta de espécies nativas do Cerrado. Enciclopédia Biosfera, 15(27), 192199.

Vazquez, G. H., Cardoso, R. D., \& Peres, A. R. (2014). Tratamento químico de sementes de milho e o teste de condutividade elétrica. Bioscience Journal, 30(3), 773-781.

Recebido: 20 de fevereiro, 2020.

Aprovado: 25 de março, 2020.

Publicado: 25 maio 2020.

Licenciamento: Este artigo é publicado na modalidade Acesso Aberto sob a licença Creative Commons Atribuição 4.0 (CC-BY 4.0), a qual permite uso irrestrito, distribuição, reprodução em qualquer meio, desde que o autor e a fonte sejam devidamente creditados. 